\title{
Sonic Hedgehog Promotes Neuronal Differentiation of Murine Spinal Cord Precursors and Collaborates with Neurotrophin 3 to Induce Islet-1
}

\author{
Renée Dutton, ${ }^{3}$ Toshiya Yamada, ${ }^{2}$ Ann Turnley, ${ }^{1}$ Perry F. Bartlett, ${ }^{1}$ and Mark Murphy ${ }^{3}$ \\ ${ }^{1}$ Walter and Eliza Hall Institute of Medical Research, Royal Melbourne Hospital, Parkville, Victoria, Australia 3050, ${ }^{2}$ Centre \\ for Cellular and Molecular Biology, University of Queensland, Brisbane, Queensland, Australia 4067, and ${ }^{3}$ Department of \\ Anatomy and Cell Biology, The University of Melbourne, Parkville, Victoria, Australia 3052
}

Sonic hedgehog (Shh) is strongly implicated in the development of ventral structures in the nervous system. Addition of Sonic hedgehog protein to chick spinal cord explants induces floor plate and motoneuron development. Whether Shh acts directly to induce these cell types or whether their induction is mediated by additional factors is unknown. To further investigate the role of Shh in spinal neuron development, we have used low-density cultures of murine spinal cord precursor cells. Shh stimulated neuronal differentiation; however, it did not increase the proportion of neurons expressing the first postmitotic motoneuron marker Islet-1. Moreover, Shh did induce Islet-1 expression in neural tube explants, suggesting that it acts in combination with neural tube factors to induce motoneurons. Another factor implicated in motoneuron development is neurotrophin 3 (NT3), and when assayed in isolated precursor cultures, it had no effect on Islet-1 expression. However, the combination of $\mathrm{N}$-terminal Shh and NT3 induced Islet-1 expression in the majority of neurons in low-density cultures of caudal intermediate neural plate. Furthermore, in explant cultures, Shhmediated Islet-1 expression was blocked by an anti-NT3 antibody. Previous studies have shown expression of NT3 in the region of motoneuron differentiation and that spinal fusimotor neurons are lost in NT3 knock-out animals. Taken together, these findings suggest that Shh can act directly on spinal cord precursors to promote neuronal differentiation, but induction of Islet-1 expression is regulated by factors additional to Shh, including NT3.

Key words: sonic hedgehog; neurotrophin 3; Islet-1; motoneurons; spinal cord; neural tube
Early studies of spinal cord development showed that the notochord was responsible for the induction of ventral structures such as floor plate and motoneurons (for review, see Placzek, 1995). Further studies demonstrated that floor plate could also induce motoneurons (Yamada et al., 1993; Tanabe et al., 1995). A factor produced in the notochord and floor plate is Sonic hedgehog (Shh) (Echelard et al., 1993; Krauss et al., 1993; Riddle et al., 1993), and substantial evidence suggests that Shh acts as a ventralizing factor in the neural tube (Echelard et al., 1993; Riddle et al., 1993; Martí et al., 1995a). Induction of floor plate and motoneurons by notochord has been shown to be specifically blocked by Shh antibodies (Martí et al., 1995b; Ericson et al., 1996).

\footnotetext{
Received Sept. 14, 1998; revised Jan. 13, 1999; accepted Jan. 22, 1999.

This work was supported by the National Health and Medical Research Council of Australia, the Cooperative Research Centre for Cellular Growth Factors, the Bethlehem Griffiths Research Foundation and the Motor Neurone Disease Research Institute of Australia Inc. We acknowledge receipt of the anti-Isl-1 hybridoma from the Developmental Studies Hybridoma Bank maintained by the Department of Pharmacology and Molecular Sciences, Johns Hopkins University School of Medicine (Baltimore, MD), and the Department of Biological Sciences, University of Iowa (Iowa City, IA), under contract N01-HD-6-2915 from the National Institute of Child Health and Human Development. Thanks to Cheryl Augustine for help with the RT-PCR, Dr. Andrew Elefanty for confocal imaging, Janice Coventry for statistical advice, and Dr. Trevor Kilpatrick for helpful comments about this manuscript. Thanks also to Drs. David Bumcrot, Elisa Martí, and Ritsuko Takada and Professor Andy McMahon for the supply of the recombinant purified Shh-N protein. We are grateful to Dr. Leona Ling at BIOGEN for the anti-Shh antibody and Associate Professor R. A. Rush and Dr. X. F. Zhou at Flinders University for the anti-NT3 antibody.

Correspondence should be addressed to Dr. Mark Murphy, Department of Anatomy and Cell Biology, The University of Melbourne, Parkville, Victoria, Australia 3052 .

Copyright (ㄷ) 1999 Society for Neuroscience $\quad 0270-6474 / 99 / 192601-08 \$ 05.00 / 0$
}

Purified N-terminal Shh (Shh-N) has been shown to induce the development of floor plate cells and motoneurons in explants of neural plate (Roelink et al., 1994, 1995; Martí et al., 1995b). Finally, Shh null mutant animals do not develop many ventral structures of the nervous system (Chiang et al., 1996). Taken together, these data support the role of Shh as a neural tube ventralizing factor.

In many studies on motoneuron development, identification of newly developed motoneurons relied on the expression of Islet-1 (Isl-1). This LIM homeodomain transcription factor is the first marker of postmitotic motoneurons and is expressed soon after their exit from the cell cycle (Ericson et al., 1992). All motoneurons pass through a period of Isl-1 positivity, but not all motoneurons remain Isl-1-positive (Tsuchida et al., 1994). Spinal motoneurons failed to develop in Isl-1 null mutant embryos, establishing Isl-1 as a key regulator of motoneuron development (Pfaff et al., 1996).

It is thus likely that the growth factors that regulate Isl-1 expression in the ventral region of the spinal cord are the determining epigenetic factors in motoneuron specification. Because Shh induces Isl-1 in explant cultures of neural plate, it is the prime candidate for this specifying role. However, Isl-1 induction assays are conducted with neural tube explants, which may produce a range of factors endogenously. In such assays, it cannot be determined whether Shh acts directly or in association with other factors. We have studied the action of Shh-N in low-density cultures of isolated spinal cord precursors, where the effects of growth factors are likely to be direct. We report here that purified Shh-N increased the number of neurons in isolated precursor 
cultures; however, it had no effect on Isl-1 expression. Another factor implicated in motoneuron development is neurotrophin 3 (NT3) (Averbuch-Heller et al., 1994; Roelink et al., 1995). In our cultures, NT3 had no effect on Isl-1, but the combination of NT3 and Shh-N resulted in Isl-1 expression in almost all neurons generated. Moreover, Shh-N-induced Isl-1 expression in explant cultures was blocked with an antibody to NT3, suggesting that NT3 is the endogenous factor that acts specifically with Shh-N to induce Isl-1.

\section{MATERIALS AND METHODS}

Isolation of spinal cord cells. Pregnant CBA mice were killed by cervical dislocation at embryonic day 10 (E10) of gestation, where E0 is the day of vaginal plug detection. Embryos were collected into HEPES-buffered Eagle's medium (HEM; Life Technologies, Gaithersburg, MD) and developmentally staged (Theiler, 1989). The dissection procedure has been described in detail elsewhere (Drago et al., 1991; Richards et al., 1992; Yamada et al., 1993). For studies on neuronal differentiation and neurite extension, embryos were transected below the otic vesicle and in the center of the hindlimb bud. For studies on motoneuron differentiation, the section of spinal cord used extended from the center of the hindlimb bud to three somites rostrally. The caudal spinal cord was further dissected, and the intermediate region of the spinal cord, termed the intermediate neural plate, was used to study the differentiation of Isl- $1^{+}$neurons (Yamada et al., 1993). Tissue was either retained for explant cultures (see below) or dissociated as previously described (Drago et al., 1991; Richards et al., 1992).

Culture of dissociated spinal cord cells and caudal spinal cord explants. Sixty-well microplates (Lux) were coated with poly-DL-ornithine (0.5 $\mathrm{mg} / \mathrm{ml}$; Sigma, St. Louis, MO) for $1 \mathrm{hr}$, washed three times with HEM, and allowed to air dry. Plates were then coated with laminin $(20 \mu \mathrm{g} / \mathrm{ml}$; Collaborative Biomedical Products, Bedford, MA) for $1 \mathrm{hr}$ and washed once with HEM. The media were aspirated immediately before plating cells (150 cells per well) in Monomed (Life Technologies) with part A supplement [MMA, Commonwealth Serum Laboratories (CSL)]. Purified recombinant Shh-N (Martí et al., 1995b) (used at $800 \mathrm{ng} / \mathrm{ml}$ unless otherwise stated), recombinant NT3 protein (50 ng/ml; Pepro-Tech), anti-Shh antibody $(10 \mu \mathrm{g} / \mathrm{ml})$ (Ericson et al., 1996), anti-NT3 antibody (Zhou and Rush, 1994) (used at $10 \mu \mathrm{g} / \mathrm{ml}$ in isolated cultures or 100 $\mu \mathrm{g} / \mathrm{ml}$ in explant cultures), or conditioned medium from COS cells transfected with Shh-N plasmid or mock-transfected COS cells $(50 \% \mathrm{v} / \mathrm{v})$ was added to the cultures. The cultures were then incubated at $37^{\circ} \mathrm{C}$ in $5 \% \mathrm{CO}_{2}$ in air for between 1 and $72 \mathrm{hr}$ and then counted and/or fixed and processed for immunohistochemistry as described below.

Where total neuron counts were assessed, cultures were counted both under phase microscopy and after staining with neuronal markers (see below). Every cell that was counted as a neuron under phase microscopy (a phase-bright cell body with at least one process longer than the diameter of the cell body) was also stained with neurofilament (NF) or microtubule-associated protein 2 (MAP2). For the time course experiment, individual cells were followed over the course of the experiment, and neurons were identified by morphological criteria. Where the proportion of Isl- $1^{+}$neurons was determined, cells were counted on the basis of morphology and immunoreactivity for Isl-1 (see below). Some of these cultures were double stained for Isl-1 and NF as final confirmation of neuronal identity. These results are expressed as the number of Isl- $1^{+}$ neurons as a percentage of total neurons, except for the first explant culture experiments (see Fig. 5), in which the number of Isl- $1^{+}$cells is expressed per explant.

Individual intermediate neural plates were cultured in threedimensional collagen gels as described by Yamada et al. (1993). Explants were cultured for $40 \mathrm{hr}$ in $400 \mu \mathrm{l}$ of MMA serum-free medium in the presence of purified Shh-N or the various COS cell conditioned media. Cultures were fixed with Zamboni's fixative for $2 \mathrm{hr}$ at $4^{\circ} \mathrm{C}$, washed, triplestained for neurofilament, Isl-1, and 4',6-diamidino-2-phenylindole (DAPI; see below), and examined using fluorescence or confocal microscopy.

Immunohistochemistry. NF staining has been previously described (Richards et al., 1992). The incubation buffer for the primary antibody also contained $0.8 \%$ Tween 20 . Isolated cell cultures were washed three times for $5 \mathrm{~min}$ each, and explant cultures were washed three times for 45 min each. For fluorescence microscopy, the cells were incubated for 30 min with a rhodamine-conjugated sheep anti-rabbit IgG antibody (1:100; Silenus, Hawthorn, Victoria, Australia) and washed an additional three times. For peroxidase staining, the previously described method was used
(Richards et al., 1992). Cultures were then mounted in either 1,4diazabicyclo(2.2.2)-octane (DABCO; Merck, Munich, Germany) in glycerol (Murphy et al., 1990) for fluorescence confocal microscopy or with Aquamount mountant (BDH Chemicals, Poole, England) for peroxidase staining. $\mathrm{NF}^{+}$cells and processes were detected by fluorescence microscopy, and peroxidase-stained cultures were examined by bright-field microscopy.

For MAP2 and Isl-1 staining, cultures were fixed with Zamboni's fixative at $4^{\circ} \mathrm{C}$ for $1 \mathrm{hr}$, washed three times with PBS and $1 \% \mathrm{FBS}(\mathrm{v} / \mathrm{v}$; Cytosystems), and then incubated for $30 \mathrm{~min}$ in PBS, $1 \%$ FBS (v/v), $0.8 \%$ Tween 20, and $0.5 \%$ normal horse serum (CSL). After washing, the cultures were incubated for either $30 \mathrm{~min}$ with a mouse anti-MAP2 antibody (1:400 Sigma) or overnight at $4^{\circ} \mathrm{C}$ with an anti-mouse, anti-Isl-1 antibody (1:100; Developmental Studies Hybridoma Bank, Iowa City, IA). Cultures were washed, and a biotinylated horse anti-mouse IgG antibody (1:200; Vector Laboratories, Burlingame, CA) was added for 30 min. Immunoreactivity was detected by peroxidase as described above.

For immunofluorescence detection of Isl-1 staining, cultures were incubated with a fluorescein-conjugated sheep-anti-mouse IgG antibody (1:100, Silenus) for $30 \mathrm{~min}$, washed, and then mounted in DABCO. For double-labeling experiments with NF and Isl-1, cultures were fixed with Zamboni's fixative for $1 \mathrm{hr}$ at $4^{\circ} \mathrm{C}$ and incubated with both primary antibodies at $4^{\circ} \mathrm{C}$ overnight. To determine total cell numbers, cultures were also incubated overnight with DAPI $(500 \mathrm{ng} / \mathrm{ml}$; Molecular Probes, Eugene, OR). After washing, the cultures were incubated with a fluorescein-conjugated sheep-anti-mouse IgG antibody (1:100, Silenus) and a rhodamine isothiocyanate-conjugated sheep anti-rabbit IgG $(1: 100$, Vector) for $30 \mathrm{~min}$. Cultures were washed, mounted in DABCO, and examined by fluorescence confocal microscopy.

Constructs and transfections. Conditioned medium containing Shh-N was derived from COS cells transfected with Shh-N plasmid DNA (for construct details, see Roelink et al., 1995). Briefly, $100 \mu \mathrm{l}$ of $0.33 \mathrm{mg} / \mathrm{ml}$ LipofectAMINE (Life Technologies) and $100 \mu \mathrm{l}$ of plasmid Shh-N (1 $\mu \mathrm{g}$ of DNA) were incubated together at room temperature for $30 \mathrm{~min}$. DMEM with $1 \%$ glutamine was added to the Shh-N DNALipofectAMINE mixture to make up $1 \mathrm{ml}$. A semiconfluent monolayer of COS cells in a $35 \mathrm{~mm}$ tissue culture dish was washed once with DMEM (Life Technologies) and $1 \%$ glutamine. The media were then removed, and $800 \mu \mathrm{l}$ of the LipofectAMINE solution was added. Cells were incubated for $5 \mathrm{hr}$ at $37^{\circ} \mathrm{C}$ in $5 \% \mathrm{CO}_{2}$ in air, medium was changed to DMEM, $10 \%$ FBS, and $1 \%$ glutamine, and cells were cultured overnight. The cultures were then washed and cultured in OPTI-MEM (Life Technologies) serum-free medium for $60 \mathrm{hr}$ before conditioned medium was collected.

RT-PCR detection of NT3 in COS-M6 cells. Total RNA was prepared from mouse kidney and COS-M6 cells cultured in the presence or absence of $10 \%$ FCS using an RNeasy kit (Qiagen, Clifton Hill, Victoria, Australia). RT-PCR was performed using $1 \mu \mathrm{g}$ of total RNA with an oligo-dT $\mathrm{d}_{15}$ primer (Promega, Madison, WI) and Superscript II reverse transcriptase (Life Technologies), according to the manufacturers instructions. Aliquots of each sample were taken for PCR using Taq DNA polymerase (Life Technologies) and primers to amplify NT3 (sense, 5'-GTGGCATCCAAGGCAACAGCATGG-3'; antisense, 5'-CGGTCACCCACAGGCTCTCACTGTC-3') or actin (sense, 5'-CTGAAGTACCCCATTGAACATGGC-3'; antisense, 5'-CAGAGCAGTAATCTCCTTCTGCAT- $3^{\prime}$ ). PCR was performed for 35 cycles of $94^{\circ} \mathrm{C}$ for 1 min, $55^{\circ} \mathrm{C}$ for $1 \mathrm{~min}$, and $72^{\circ} \mathrm{C}$ for $2 \mathrm{~min}$, and samples were then analyzed on a $2 \%$ agarose gel.

Statistics and image analysis. All data are expressed as mean $\pm \mathrm{SD}$. Tests of significance for the distribution of neurites were performed using the Mann-Whitney $U$ test. The comparison of two means was analyzed using a Student's $t$ test, and comparisons of greater than two means were analyzed using a one-way ANOVA with the Sheffé post hoc test (Zar, 1984). The errors for the percentile data are expressed as the $\mathrm{SD}$, and corrections for statistical calculations on percentile data were made using the arcsine transformation (Zar, 1984). Image analysis was performed using a Nikon microscope linked to a video display unit. Measurements of neurite length were made using the Videotrace system, version 3 (Microsoft).

\section{RESULTS}

\section{Purified Shh-N promotes neuronal differentiation from} isolated spinal cord precursors

To examine what influence Shh-N might have on the development of individual precursors from the murine spinal cord, the neural 

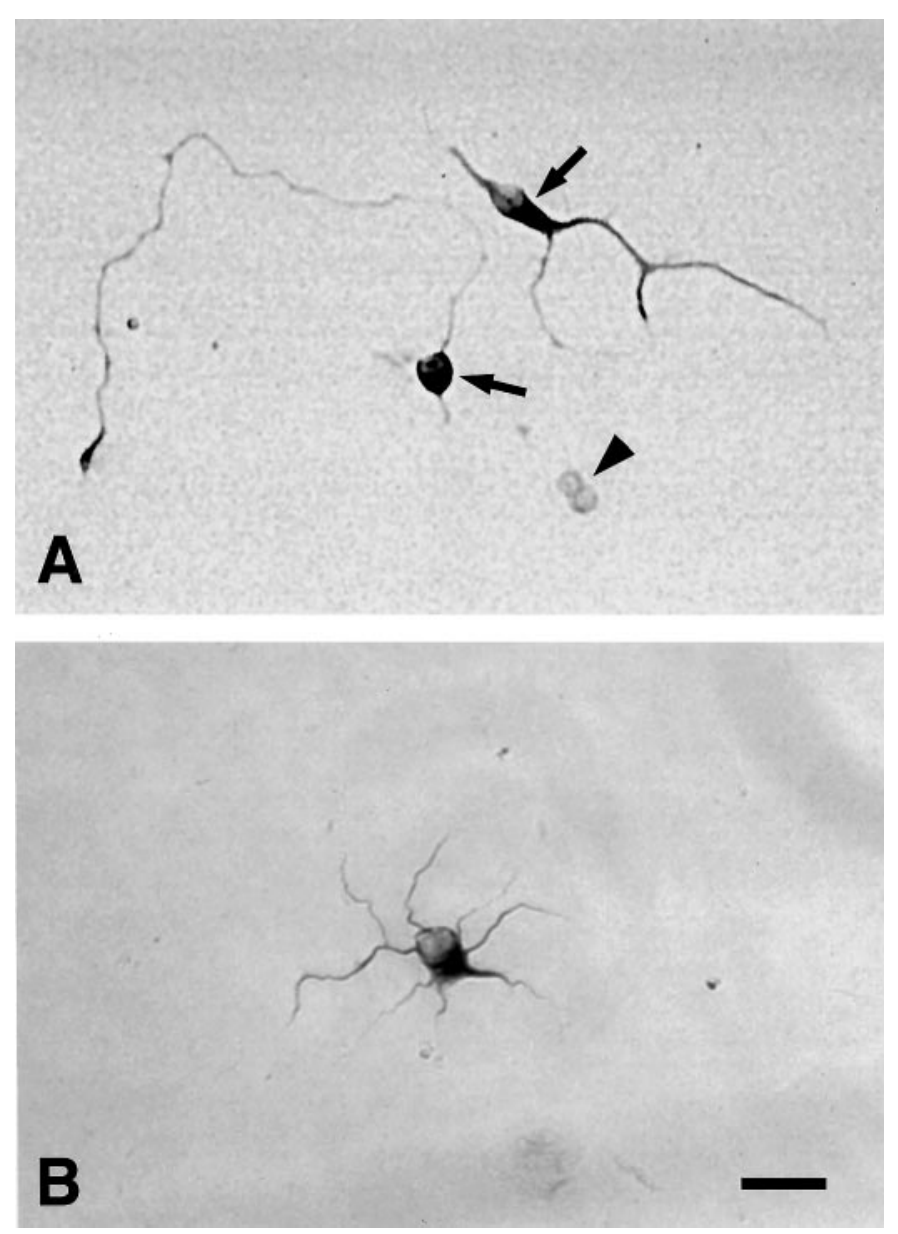

Figure 1. Neurons generated in isolated precursor cultures (both Shh$\mathrm{N}$-treated and controls) expressed the neuronal markers MAP2 ( $A$, arrow) and $150 \mathrm{kDa} \mathrm{NF}(B)$, whereas undifferentiated precursors were negative for these markers $(A$, arrowhead). Scale bar, $50 \mu \mathrm{m}$.

tube from E10 mice was dissected and dissociated into single cells. The isolated spinal cord precursors were then cultured at low density in the presence or absence of Shh-N. Neurons were identified both by morphology and immunoreactivity for MAP2 or $150 \mathrm{kDa} \mathrm{NF}$ (Fig. $1 A, B$ ). Shh-N stimulated a twofold to threefold increase in the number of neurons compared with control cultures. The stimulation of cell number by Shh-N appeared to be restricted to the differentiation of new neurons, because Shh-N had no effect on total cell number (control, $67 \pm$ 14; Shh-N, $69 \pm 13$ ) in these cultures. The generation of neurons in response to Shh-N occurred in a fairly narrow concentration range, with a maximum effect over $100 \mathrm{ng} / \mathrm{ml}$ (Fig. 2). The maximum number of neurons that developed in response to Shh-N occurred within 18-20 hr of plating (Fig. 3), after which the neurons began to die. By $48 \mathrm{hr}$ after plating, all cells in both Shh-N-treated and control cultures were dead (Fig. 3).

In addition to the increase in neuronal number, cultures treated with purified Shh-N contained neurons with longer neurites in comparison with controls. Using image analysis, the lengths of all neurites were measured from 100 individual neurons in control and Shh-N-treated cultures. The distribution of neurite length of the two populations was significantly different, showing that the population of neurons treated with Shh-N contained longer neurites than the control population of neurons. The difference was

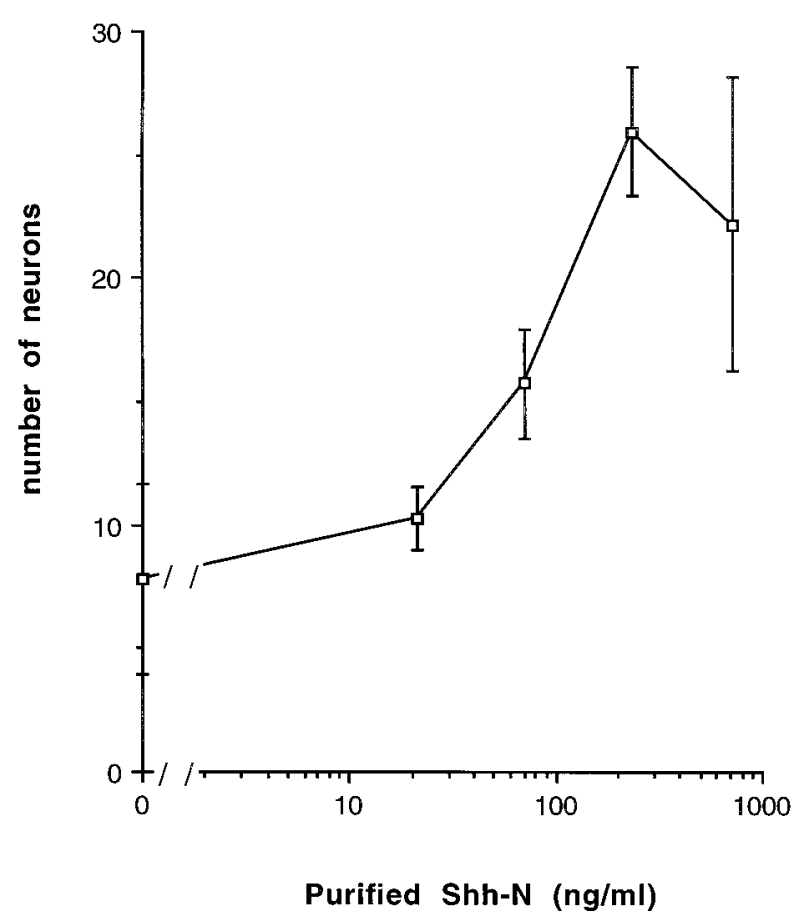

Figure 2. Neurons generated in response to increasing concentrations of purified Shh-N after $18 \mathrm{hr}$ in culture. Values are means \pm SD of a representative experiment $(n=6)$, and the experiment was performed 12 times.

observed when neurons were quantified in terms of the total length of all neurites emanating from the cell soma (Fig. 4) as well as when the longest neurite was measured from the same population ( $p<0.001$; data not shown). Thus, purified Shh-N stimulated an increase both in the number of neurons generated in isolated precursor cultures and in neurite outgrowth.

\section{Shh-N promotes Isl-1 expression in explant cultures of murine neural tube but not in isolated spinal cord precursors}

Previous studies have shown that purified Shh-N protein induces Isl-1 expression in explants of chick caudal intermediate neural plate (Martí et al., 1995a; Roelink et al., 1995). To determine whether Shh had a similar ability to induce Isl-1 in murine tissue, the intermediate region of the caudal murine spinal cord was isolated for explant culture. This region represents a population of cells that are still multipotential and are less likely to have signals that direct dorsal and ventral cell fate (Yamada et al., 1993). Explants were cultured for $40 \mathrm{hr}$ in the presence of different concentrations of purified Shh-N, (Fig. $5 A-F$ ), and a dosedependent increase in the number of Isl- $1^{+}$cells was observed (Fig. 5G). At the highest concentration of Shh-N, almost all cells in the explant stained positively for Isl-1. Thus Shh-N can stimulate the expression of Isl-1 in a high proportion of cells in murine explants.

The microenvironment of the explant in association with Shh-N may have influenced Isl-1 expression. To minimize this effect, precursor cells isolated from the caudal intermediate region of the neural plate were dissociated and cultured at low cell density (150 cells plated per well) in the presence of different factors. Regardless of culture conditions, $20 \%$ of cells plated (30 cells per well) survived, and of these the majority (90\%) were neuronal. Isl- $1^{+}$neurons developed under these conditions (Fig. 


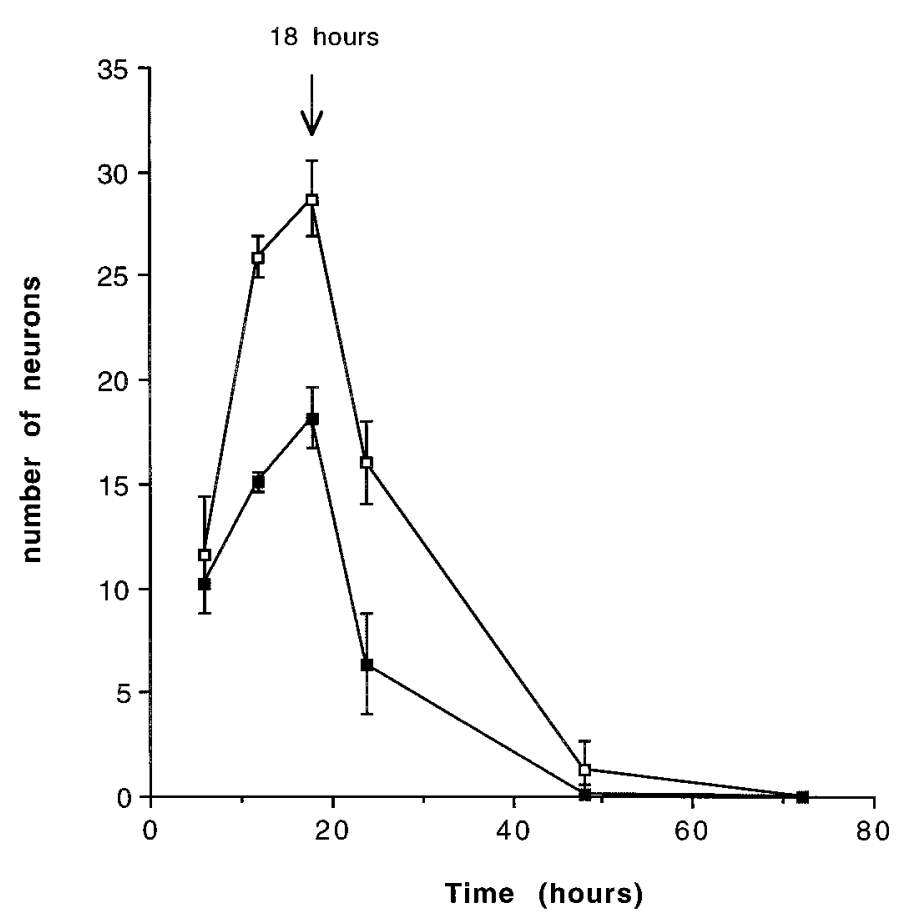

Figure 3. Time course of the appearance of neurons in response to 250 $\mathrm{ng} / \mathrm{ml}$ purified Shh-N. The peak time of neuronal differentiation in these cultures in both Shh-N-treated (open square) and control cultures (closed square) occurred at $18 \mathrm{hr}$ of culture, and by $48 \mathrm{hr}$ in culture most cells were dead. Values are means $\pm \mathrm{SD}$ of a representative experiment $(n=6)$, and the experiment was performed twice.

$6 A, B)$; however, exogenous Shh-N had no additional effect on Isl-1 expression (Figs. 7, 8A). A wide concentration range of Shh-N, including that previously shown to induce Isl-1 in explants (Roelink et al., 1995), had no significant effect on Isl-1 expression (Fig. 7B).

Over the $18 \mathrm{hr}$ culture period there was an increase in the proportion of Isl- $1^{+}$neurons, independent of added Shh-N, because only $5 \%$ of the cells were Isl- $1^{+}$at the time of isolation (data not shown). This increase in Isl-1 expression could have been a consequence of endogenous production of Shh in the cultures. To examine this possibility, the cells were cultured with an anti-Shh antibody, which resulted in 9\% less $(p<0.05)$ Isl- $1^{+}$ neurons compared with controls. This indicates that endogenous Shh is responsible for a small but significant proportion of Isl-1 expression in these cultures; however, most endogenous stimulation of Isl-1 is not attributable to Shh.

\section{NT3 and Shh are both required for the neuronal expression of Isl-1 in isolated spinal cord precursor cultures}

It has been reported that a greater number of Isl-1-positive cells developed in chick explant cultures when conditioned medium from COS cells expressing Shh-N (ShhCM) was used compared with control or purified Shh-N-treated cultures (Roelink et al., 1995). These experiments suggest that factors produced by the COS cells may stimulate Isl-1 expression in spinal cord neurons. To further examine this possibility, isolated precursors from the caudal intermediate neural plate were cultured in the presence of ShhCM. Whereas there was no increase in neuronal number, there was a marked increase in the number of Isl- $1^{+}$neurons found compared with control or Shh-N-treated cultures (Fig. 7).

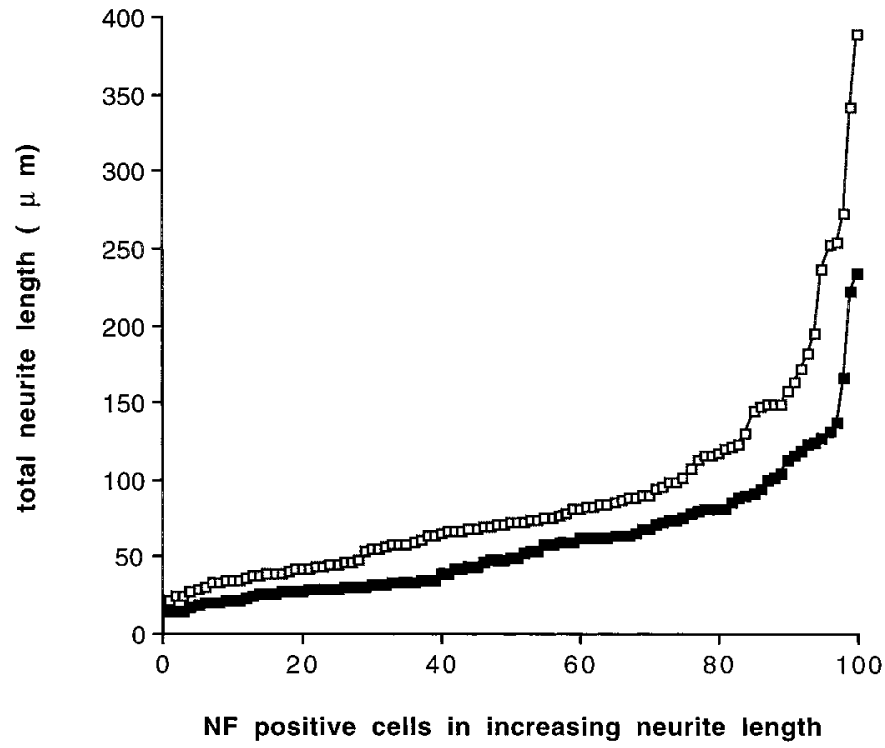

Figure 4. Distribution of neurite length of 100 randomly selected neurons generated in either Shh-N-treated (open square) or control (closed square) cultures. The distribution of neurite lengths in the two populations was significantly greater in the Shh-N-treated cultures $\left({ }^{*} p<0.001\right.$; see Materials and Methods for statistical details).

This result indicated that the Shh-N produced by the COS cells was either structurally different from the Escherichia coliproduced protein, or that COS cells produce a factor that acts in association with purified Shh-N to induce Isl-1 expression in neurons. To distinguish between these two possibilities, isolated precursors were cultured with purified $E$. coli Shh-N protein and conditioned medium from mock-transfected COS cells (COSCM). Similar to the ShhCM-treated cultures, there was an $\sim 100 \%$ increase in the number of Isl- $1^{+}$neurons under these conditions. This corresponds to $\sim 80 \%$ of the neurons in culture expressing Isl-1. Neither the purified Shh-N nor COSCM alone increased Isl-1 expression in neurons over control levels (Fig. 7). Thus, the two forms of Shh-N (E. coli- and COS cell-derived) in association with COSCM generated similar effects on Isl-1 expression in neurons generated in isolated precursor cultures. This suggests that other factors can act in combination with Shh-N to stimulate Isl-1 expression in spinal neurons.

It has also been reported that in chick explant cultures NT3 and Shh-N together generated a slight increase in the number of Isl-1-positive neurons compared with Shh-N alone (Roelink et al., 1995). Thus, we examined the effects of NT3, and a number of other factors implicated in motoneuron development, on the isolated precursors. Leukemia inhibitory factor (LIF), NT3, brain-derived neurotrophic factor (BDNF), and glial cell linederived neurotrophic factor (GDNF) were used alone and in association with purified Shh-N. LIF but not NT3, BDNF, or GDNF promoted an increase in the number of morphological, $\mathrm{MAP}^{+}$neurons (data not shown). The combination of LIF, NT3, BDNF, or GDNF with Shh-N did not further increase the number of neurons in culture, nor did these combinations increase survival of any cells in culture (data not shown). Furthermore, none of these factors independently induced Isl-1 expression over control levels (data not shown). However, treatment with both NT3 and purified Shh-N resulted in an increased number of neurons expressing Isl-1 in these cultures (Fig. $8 A$ ). No 

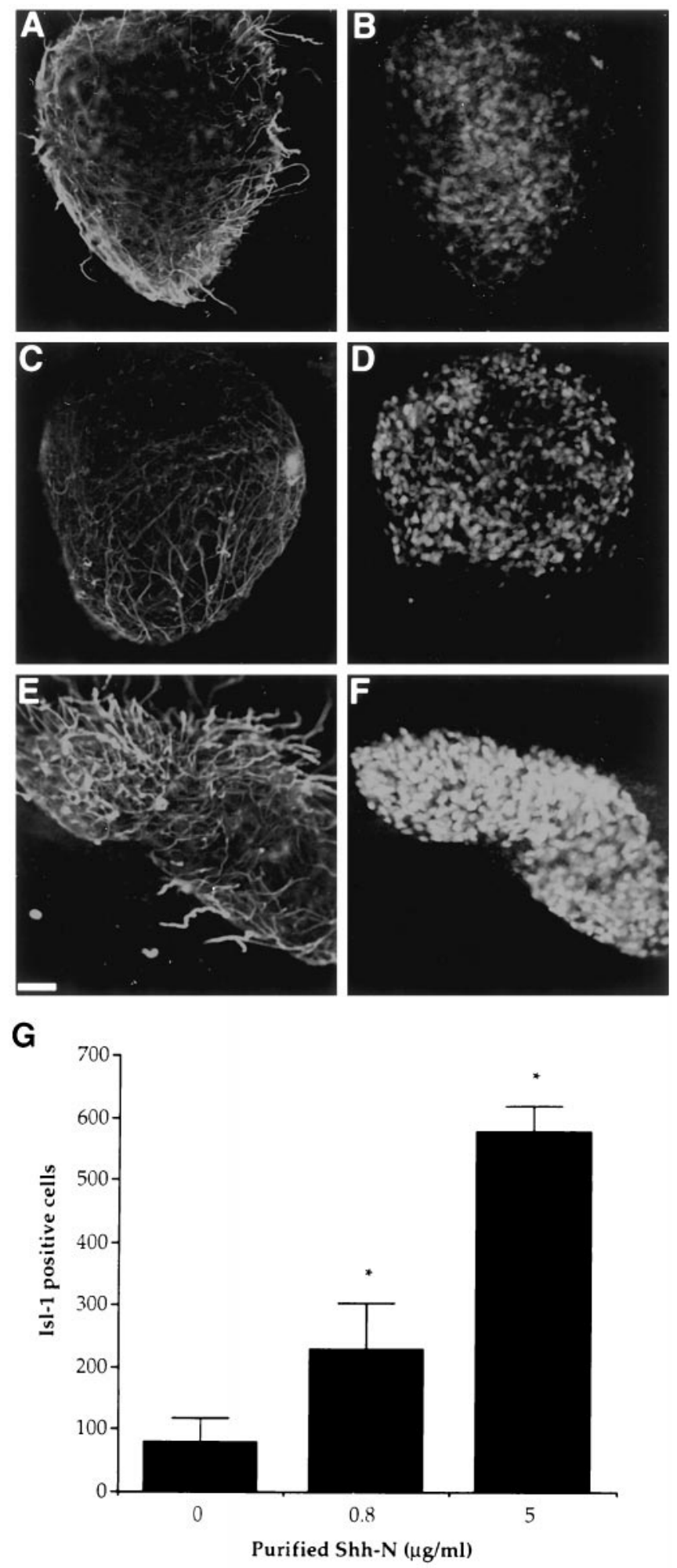

Figure 5. Purified Shh-N induced an increase in the number of Isl-1 ${ }^{+}$ neurons in murine explant cultures over $40 \mathrm{hr}$. Confocal images show control $(A, B), 800 \mathrm{ng} / \mathrm{ml}$ Shh-N-treated $(C, D)$, and $5 \mu \mathrm{g} / \mathrm{ml}$ Shh-Ntreated $(E, F)$ cultures stained for $150 \mathrm{kDa} \mathrm{NF}$ (red) and Isl-1 (green). Quantification of Isl-1 staining in these cultures $(G)$ showed a significant $\left({ }^{*} p<0.001\right)$, dose-dependent increase in response to Shh-N. Values are means $\pm \mathrm{SD}$ of a representative experiment $(n=3)$, and the experiment was performed three times. Scale bar, $50 \mu \mathrm{m}$.
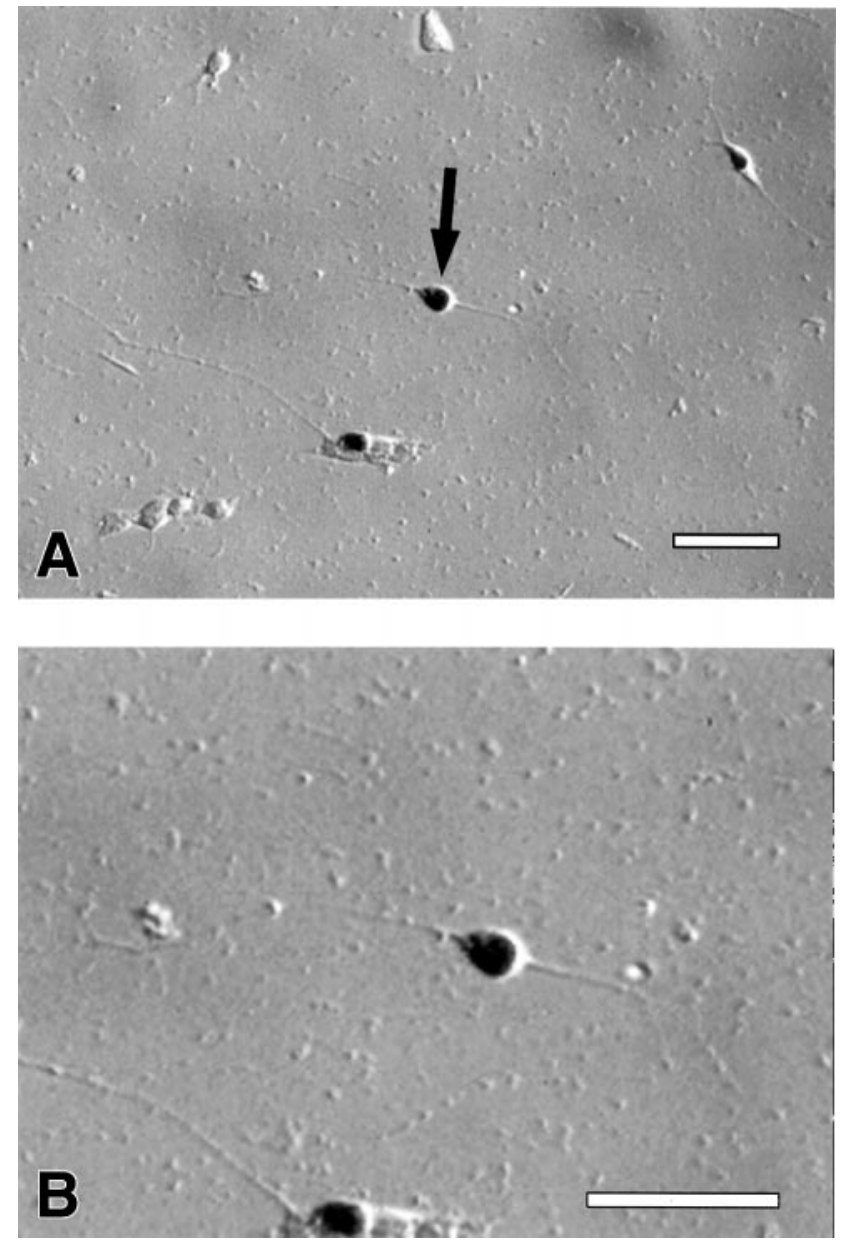

Figure 6. $A$, Expression of Isl-1 in isolated neurons treated with purified Shh-N. $B$, Higher-power view of neuron marked witn an arrow in $A$, showing Isl- $1^{+}$neuron with long process. Scale bar, $100 \mu \mathrm{m}$.

other combination enhanced the effect of purified Shh-N on Isl-1 induction.

Because Shh-N plus NT3 increased the number of neurons expressing Isl-1 in isolated precursor cultures, we examined whether an anti-NT3 antibody could inhibit the Isl-1 induction mediated by the ShhCM in isolated precursor cultures. The specificity of this antibody has previously been shown (Zhou and Rush, 1993). In addition, in our assay, treatment with this antibody blocked the increase in Isl-1 expression induced by NT3 in the presence of Shh. Under these conditions, the level of Isl-1 induction was reduced to control levels (Fig. 8A). Furthermore, mRNA for NT3 was detected in the COS cells using RT-PCR (Fig. $8 B$ ). This result suggests that NT3 may be the factor in COSCM that acts in combination with Shh to induce Isl-1 in spinal neurons.

Given these findings, we next investigated whether NT3 is produced endogenously in explant cultures, and whether it acts with Shh-N to induce Isl-1. Caudal intermediate neural plate explants were cultured with Shh-N in the presence or absence of the anti-NT3 antibody. We found that the Isl-1 expression induced by Shh-N in these cultures was effectively blocked with the addition of the anti-NT3 antibody ( $p<0.01$; Fig. 9). Furthermore, this inhibition could be competed out with the addition of exogenous NT3 (data not shown). 


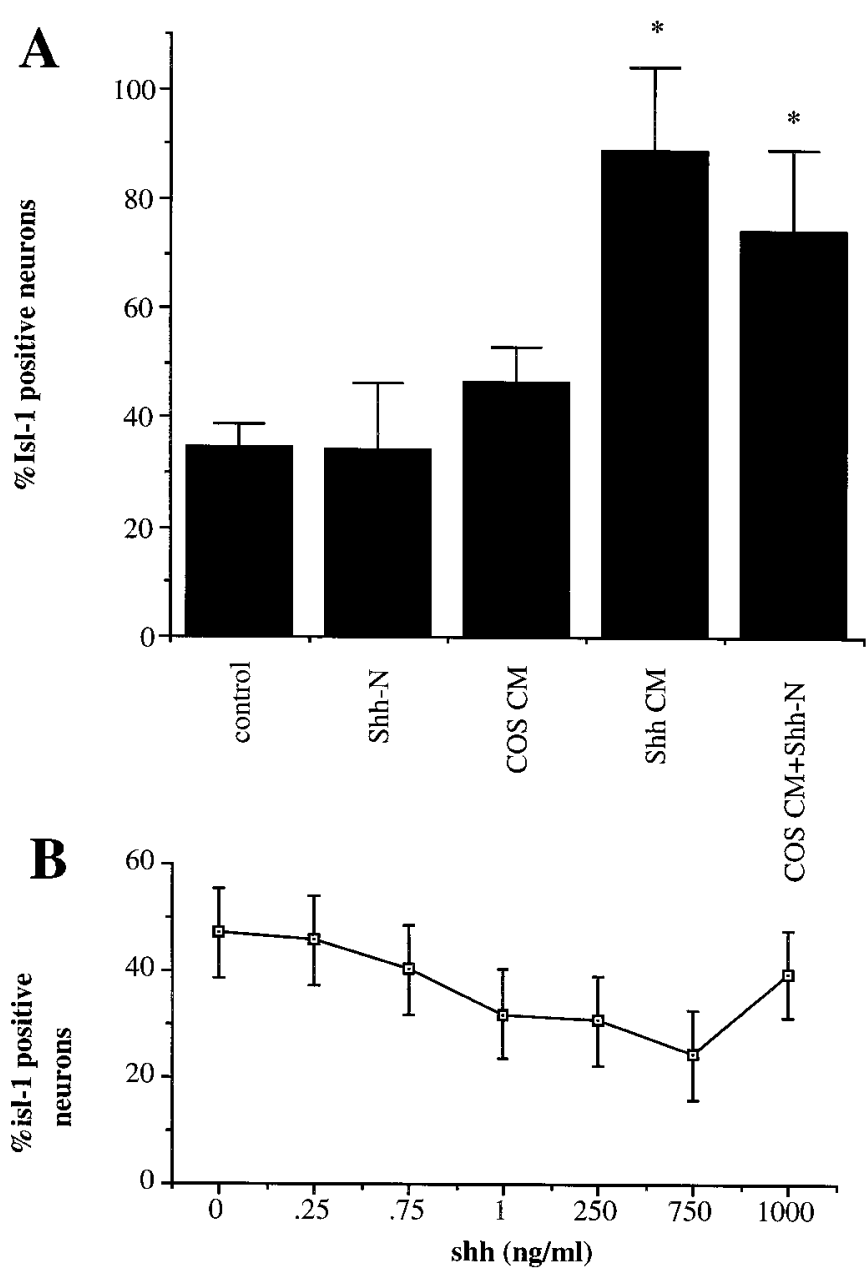

Figure 7. In isolated precursor cultures purified Shh-N failed to increase the neuronal expression of Isl-1, whereas ShhCM and COSCM plus purified Shh-N stimulated a significant increase in Isl-1 expression compared with control $\left({ }^{*} p<0.005\right)$. A, Neither purified Shh-N nor COSCM alone had a significant effect on Isl-1 expression compared with control cultures, and there was no significant difference between the effects of ShhCM and COSCM plus Shh-N. Values are means \pm SD of a representative experiment $(n=6)$, and the experiment was performed 10 times. $B$, A titration analysis shows that no concentration of purified Shh-N within the range of $1 \mathrm{pg} / \mathrm{ml}$ to $1 \mu \mathrm{g} / \mathrm{ml}$ has any significant effect on Isl-1 expression.

\section{DISCUSSION}

\section{Shh-N promotes neuronal differentiation in isolated spinal cord precursor cultures}

This study shows that purified Shh-N can increase the number of neurons generated from spinal cord precursors at low cell density, at which the interaction is likely to be direct. The twofold to threefold increase in neurons was not accompanied by an increase in cell number, suggesting that the increase was not associated with cell proliferation but reflected an increase in differentiation. The transient increase in neuronal number suggests that Shh-N does not act as a survival agent for newly generated neurons, further supporting the idea that Shh-N promotes differentiation of precursors.

Neurons generated in Shh-N-treated cultures had longer neurites than neurons in control cultures. Shh has been reported to stimulate neurite outgrowth (Martí et al., 1995a) and is expressed in the axon tract between prosomeres 2 and 3 in the diencephalon
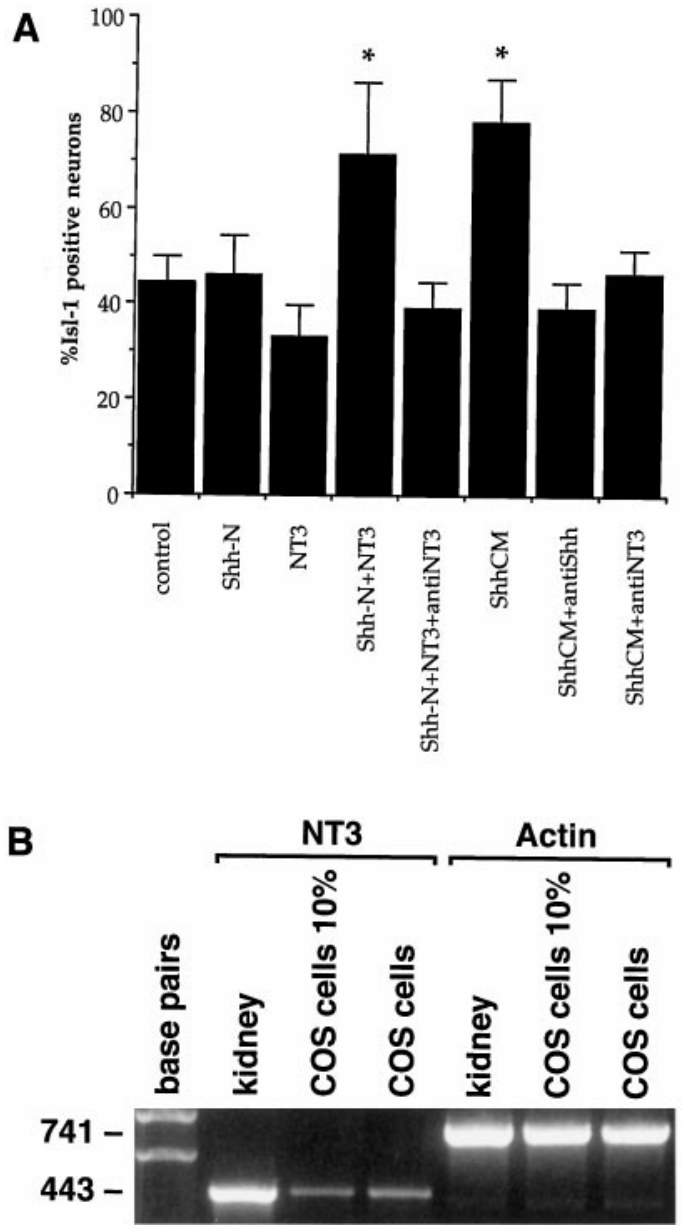

Figure 8. Shh-N requires NT3 to induce additional Isl-1 in isolated precursor cultures. Anti-NT3 antibody totally inhibited the increase in Isl-1 expression observed with ShhCM or purified Shh plus NT3 $\left({ }^{*} p<\right.$ $0.005 ; A)$. Values are means $\pm \mathrm{SD}$ of a representative experiment $(n=6)$; the experiment with all conditions was performed twice, and in separate combinations it was performed seven times. NT3 mRNA is present in COS cells cultured in $10 \%$ serum (COS cells $10 \%$ ) or in serum-free conditions (COS cells; $B$ ). NT3 is also present in mouse kidney mRNA, which serves as a positive control for the reaction.

(Figdor and Stern, 1993). Shh has also been detected lining commissural axon tracts when they begin to project across the floor plate (Martí et al., 1995a). Therefore, Shh may have a role in axonal outgrowth, and our results are consistent with this role.

When cells were isolated and cultured from a specific region of the spinal cord, the caudal intermediate neural plate, Shh-N had no significant stimulatory effect on neuronal differentiation. The caudal intermediate neural plate was selected because it represents a more homogeneous population of multipotential precursor cells. Compared with the whole spinal cord, it is at an earlier developmental stage. It is possible that the cells that respond to the differentiation effects of Shh-N are not present in caudal intermediate neural plate cultures or that they require additional factors for neuronal differentiation.

\section{Shh-N induces Isl-1-positive neurons in intermediate neural plate explants but not in isolated cells}

We specifically used caudal intermediate neural plate for our assays of Isl-1 induction because of their multipotential nature (Yamada et al., 1993), and there is no synthesis of Shh in this 


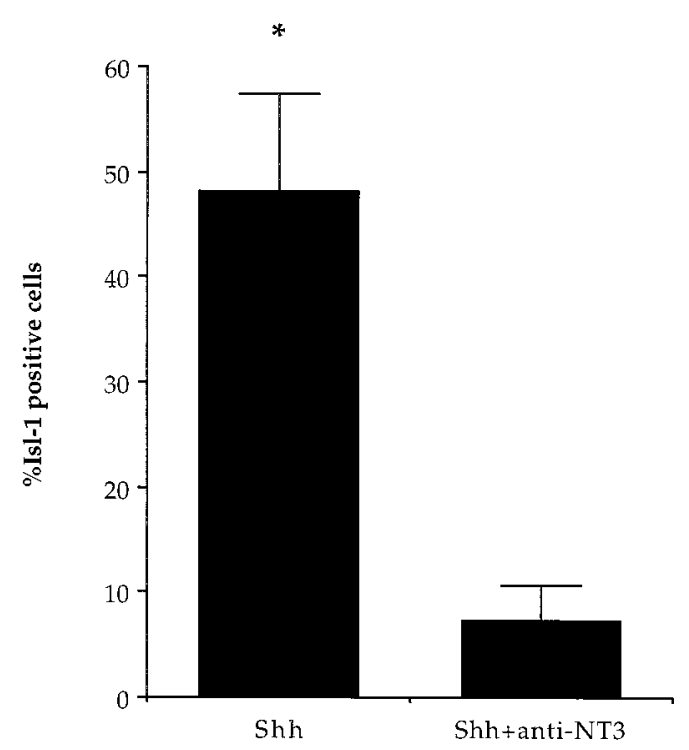

Figure 9. Inhibition of endogenous NT3 by the anti-NT3 antibody significantly inhibited the Shh-induced expression of Isl-1 in explant cultures $\left({ }^{*} p<0.01\right)$. Values are means $\pm \mathrm{SD}$ of a representative experiment $(n=$ 5 ), and the experiment was performed twice.

region (Martí et al., 1995a). As shown in this study using mouse tissue and in previous studies using chick tissue (Roelink et al., 1994; Martí et al., 1995a; Tanabe et al., 1995), Shh-N added to spinal cord explant cultures was sufficient to induce Isl-1 expression. However, purified Shh-N failed to increase expression of Isl-1 in cultures of isolated precursor cells. Thus, factors or interactions present within explants are absent in low-density cultures. Soluble molecules or cell-cell interactions within explants may be required for Shh to induce Isl-1. Processing of Shh by explants may have modified it to an active form. There are two known modifications to the Shh protein: glycosylation (Bumcrot et al., 1995) and addition of cholesterol (Porter et al., 1996), both of which require the $\mathrm{C}$-terminal fragment of Shh to afford the changes. Because we always used Shh-N, such modifications are unlikely to account for differences in Isl-1 expression in explants and isolated cell cultures. Alternatively, explants may provide other growth factors that contribute to Isl-1 induction, as discussed below.

A difference observed in our murine cultures, compared with chick (Martí et al., 1995b; Roelink et al., 1995), was that control cultures of both isolated precursors and explants showed significant Isl-1 induction. A possible reason for this is that tissue used in our experiments was developmentally older than chick tissue, and motoneuron specification may have already occurred. However, studies of cell division in the mouse spinal cord report that, in more caudal regions, motoneuron precursor division does not peak until E11 (Nornes and Carry, 1978). This suggests that motoneuron specification is also not complete in these caudal regions by this time. Thus our population of cells, isolated from intermediate regions of E10 caudal neural plate, presumably only contains a small percentage of committed motoneurons. Consistent with this idea, at the initiation of culture, only $5 \%$ of cells expressed Isl-1. The endogenous increase in Isl-1 expression over the culture period may be attributable to murine tissue already having been exposed to inductive effects of factors in vivo, but the cells had not begun to express Isl-1 at the time of isolation. The small reduction in Isl-1 expression observed when isolated precur- sor cultures were supplied with anti-Shh antibody shows that Shh-N is responsible for part of the endogenous Isl-1 expression. Other factors may also be involved in this endogenous Isl-1 induction.

\section{Shh-N and NT3 co-operate to induce IsI-1 expression in isolated spinal cord precursors and in explant cultures}

Our experiments indicate that NT3 is a factor that synergizes with Shh-N in spinal cord cultures to induce Isl-1 expression. Whereas neither factor alone had any effect on Isl-1 expression, the combination of Shh-N plus NT3 in isolated precursor cultures resulted in a $100-150 \%$ increase in the number of neurons expressing Isl-1. Furthermore, the induction of Isl-1 expression by either purified Shh-N plus NT3 or by ShhCM was inhibited by an anti-NT3 antibody. In explants, the anti-NT3 antibody inhibited Isl-1 expression induced by Shh-N by $85 \%$, providing evidence that NT3 is required for Isl-1 induction and that NT3 is an endogenous factor in neural tube that induces Isl-1 expression.

NT3 alone has been reported to stimulate motoneuron differentiation in isolated quail spinal precursor cultures (AverbuchHeller et al., 1994). In contrast to our results, the quail cultures were established at high cell density, and induction of Isl-1 occurred in only $10 \%$ of cells. Thus, these cultures (which included ventral regions of spinal cord) may have produced Shh in sufficient quantities to facilitate Isl-1 induction in the presence of exogenous NT3. Furthermore, evidence that Shh plays a critical role in motoneuron differentiation (Chiang et al., 1996; Hammerschmidt et al., 1997) suggests it is unlikely that NT3 alone would be responsible.

It is also possible that NT3 may be able to extend or restore the competence of precursor cells to differentiate into motoneurons after the normal period for differentiation. Thus, in our cultures, Shh-N and NT3 may act on cells both during and after the normal period of motoneuron differentiation and stimulate Isl-1 induction in a greater proportion of cells than that normally arising in vivo. This possibility may have important consequences for the regeneration of motoneurons in trauma and disease.

\section{Does NT3 co-operate with Shh-N in vivo to induce IsI-1?}

What is the evidence that NT3 acts in motoneuron induction in vivo? First, our explant experiments with the anti-NT3 antibody infer endogenous production of and requirement for NT3 in Isl-1 induction. Second, detailed expression studies establish that NT3 is present specifically in the developing murine lateral motor column at least as early as E10 (Farinas et al., 1996), which is relatively early during motoneurogenesis in lumbar regions of neural tube (Nornes and Carry, 1978; Lance-Jones, 1982). Additionally, there is intense expression of NT3 adjacent to and ventrolateral to the neural tube at this time. This expression pattern correlates closely with the onset of Isl-1 expression in motoneurons, which begins $4-16 \mathrm{hr}$ after the final division of motoneuron progenitors (Ericson et al., 1992). Thus, NT3 is expressed just before and/or at the time of Isl-1 expression, at the earliest stages of motoneuron development. TrkC, the receptor for NT3, is also expressed in ventrolateral regions of spinal cord at the time of motoneuron differentiation (Lamballe et al., 1994), further suggesting a role for NT3 in motoneuron specification.

Additional support for NT3 and Shh having a role in motoneuron development comes from gene-targeting studies. The Shh knock-out animals show a complete loss of ventral structures in the developing CNS, demonstrating an absolute requirement for Shh in the development of all these structures. In contrast, the 
NT3 null mutants show a far more specific phenotype in the spinal cord. These animals lose a subclass of motoneurons, the $\gamma$ or fusimotor neurons, which represent $30-40 \%$ of spinal motoneurons (Kucera et al., 1995). Correspondingly, mice lacking a functional trkC receptor show a $30 \%$ loss of motoneuron fibers in the ventral root of spinal cord (Klein et al., 1994), indicating a similar reduction in motoneuron number. However, it is unknown at what stage NT3 is required for the development of these motoneurons, that is, at the stage of differentiation or later.

It is generally accepted that Shh acts as a ventralizing factor in the neural tube (Hynes et al., 1995; Lumsden and Graham, 1995; Chiang et al., 1996), and others have shown that it acts early in spinal cord development via induction of ventral progenitors (Ericson et al., 1996). Our studies extend these observations and show that Shh-N can act directly to induce neuronal differentiation; however, motoneuron specification requires additional factors such as NT3. It is also possible that other factors, in addition to NT3, collaborate with Shh in vivo. Such other factors may be required for the development of the large skeletomotor neurons in the spinal cord or at different stages of development of the $\gamma$ motoneurons. This may account for the residual motor neurons in cultures lacking NT3 or in cultures with NT3-blocking antibodies.

Our proposal that the combination of Shh and NT3 induces the differentiation of a major subclass of ventral neurons may be an example of a general regulatory phenomenon. A related effect has been reported in the development of rostral diencephalic ventral midline cells in the forebrain, where the induction of these cells required the coordinated activity of BMP7 and Shh (Dale et al., 1997). Thus, localized expression of other factors in combination with Shh may regulate specific ventral cell fates along the rostrocaudal axis.

\section{REFERENCES}

Averbuch-Heller L, Pruginin M, Kahane N, Tsoulfas P, Parada L, Rosenthal A, Kalcheim C (1994) Neurotrophin 3 stimulates the differentiation of motoneurons from avian neural tube progenitor cells. Proc Natl Acad Sci USA 91:3247-3251.

Bumcrot DA, Takada R, McMahon AP (1995) Proteolytic processing yields two secreted forms of sonic hedgehog. Mol Cell Biol 15:2294-2303.

Chiang C, Litungtung Y, Lee E, Young KE, Corden JL, Westphal H, Beachy PA (1996) Cyclopia and defective axial patterning in mice lacking Sonic Hedgehog gene function. Nature 383:407-413.

Dale JK, Vesque C, Lints TJ, Sampath TK, Furley A, Dodd J, Placzek M (1997) Cooperation of BMP7 and SHH in the induction of forebrain ventral midline cells by prechordal mesoderm. Cell 90:257-269.

Drago J, Murphy M, Bailey KA, Bartlett PF (1991) A method for the isolation of purified murine neuroepithelial cells from the developing mouse brain. J Neurosci Methods 37:251-256.

Echelard Y, Epstein DJ, St-Jacques B, Shen L, Mohler J, McMahon JA, McMahon AP (1993) Sonic hedgehog, a member of a family of putative signaling molecules, is implicated in the regulation of CNS polarity. Cell 75:1417-1430.

Ericson J, Thor S, Edlund T, Jessell TM, Yamada T (1992) Early stages of motor neuron differentiation revealed by expression of homeobox gene Islet-1. Science 256:1555-1560.

Ericson J, Morton S, Kawakami A, Roelink H, Jessell TM (1996) Two critical periods of Sonic Hedgehog signaling required for the specification of motor neuron identity. Cell 87:661-673.

Farinas I, Yoshida CK, Backus C, Reichardt LF (1996) Lack of neurotrophin-3 results in death of spinal sensory neurons and premature differentiation of their precursors. Neuron 17:1065-1078.

Figdor MC, Stern CD (1993) Segmental organization of embryonic diencephalon. Nature 363:630-634.

Hammerschmidt M, Brook A, McMahon AP (1997) The world according to hedgehog. Trends Genet 13:14-21.
Hynes M, Porter JA, Chiang C, Chang D, Tessier-Levigne M, Beachy PA, Rosenthal A (1995) Induction of midbrain dopaminergic neurons by Sonic hedgehog. Neuron 15:35-44.

Klein R, Silos-Santiago I, Smeyne RJ, Lira SA, Brambilla R, Bryant S, Zhang L, Snider WD, Barbacid M (1994) Disruption of the neurotrophin-3 receptor gene trkC eliminates la muscle afferents and results in abnormal movements. Nature 368:249-251.

Krauss S, Concordet J-P, Ingham PW (1993) A functionally conserved homolog of the Drosophila segment polarity gene hh is expressed in tissues with polarizing activity in zebrafish embryos. Cell 75:1431-1444.

Kucera J, Ernfors P, Walro J, Jaenisch R (1995) Reduction in the number of spinal motor neurons in neurotrophin-3-deficient mice. Neuroscience 69:321-330.

Lamballe F, Smeyne RJ, Barbacid M (1994) Developmental expression of trkC, the neurotrophin-3 receptor, in the mammalian nervous system. J Neurosci 14:14-28.

Lance-Jones C (1982) Motoneuron cell death in the developing lumbar spinal cord of the mouse. Brain Res 256:473-479.

Lumsden A, Graham A (1995) Neural patterning - a forward role for hedgehog. Curr Biol 5:1347-1350.

Martí E, Takada R, Bumcrot DA, Sasaki H, McMahon AP (1995a) Distribution of sonic hedgehog peptides in the developing chick and mouse embryo. Development 121:2537-2547.

Martí E, Bumcrot DA, Takada R, McMahon AP (1995b) Requirement of $19 \mathrm{~K}$ form of Sonic hedgehog for induction of distinct ventral cell types in CNS explants. Nature 375:322-325.

Murphy M, Drago J, Bartlett PF (1990) Fibroblast growth factor stimulates the proliferation and differentiation of neural precursor cells in vitro. J Neurosci Res 25:463-475.

Nornes HO, Carry M (1978) Neurogenesis in spinal cord of mouse: an autoradiographic analysis. Brain Res 159:1-6.

Pfaff SL, Mendelsohn M, Stewart CL, Edlund T, Jessell TM (1996) Requirement for LIM homeobox gene Isl1 in motor neuron generation reveals a motor neuron-dependent step in interneuron differentiation. Cell 84:309-320.

Placzek M (1995) The role of the notochord and floor plate in inductive interactions. Curr Opin Genet Dev 5:499-506.

Porter JA, Young KE, Beachy PA (1996) Cholesterol modification of hedgehog signaling proteins in animal development. Science 274:255-259.

Richards LJ, Kilpatrick TJ, Bartlett PF, Murphy M (1992) Leukemia inhibitory factor promotes the neuronal development of spinal cord precursors from the neural tube. J Neurosci Res 33:476-484.

Riddle RD, Johnson RL, Laufer E, Tabin C (1993) Sonic hedgehog mediates the polarizing activity of the ZPA. Cell 75:1401-1416.

Roelink H, Augsburger A, Heemskerk J, Korzh V, Norlin S, Ruiz i Altaba A, Tanabe Y, Placzek M, Edlund T, Jessell TM, Dodd J (1994) Floor plate and motor neuron induction by vhh-1, a vertebrate homolog of hedgehog expressed by the notochord. Cell 76:761-765.

Roelink H, Porter JA, Chiang C, Tanabe Y, Chang DT, Beachy PA, Jessell TM (1995) Floor plate and motor neuron induction by different concentrations of the amino-terminal cleavage product of sonic hedgehog autoproteolysis. Cell 81:445-455.

Tanabe Y, Roelink H, Jessell TM (1995) Induction of motor neurons by sonic hedgehog is independent of floor plate differentiation. Curr Biol 5:651-658.

Theiler K (1989) The house mouse: atlas of embryonic development. New York: Springer.

Tsuchida T, Ensini M, Morton SB, Baldassare M, Edlund T, Jessell TM, Pfaff SL (1994) Topographic organization of embryonic motor neurons defined by expression of LIM homeobox genes. Cell 79:957-970.

Yamada T, Pfaff SL, Edlund T, Jessell TM (1993) Control of cell pattern in the neural tube: motor neuron induction by diffusible factors from notochord and floor plate. Cell 73:673-686.

Zar JH (1984) In: Biostatistical analysis (Kurtz B, ed), pp 185-196, 239-241. Upper Saddle River, NJ: Prentice Hall.

Zhou XF, Rush RA (1993) Localization of neurotrophin-3-like immunoreactivity in peripheral tissues of the rat. Brain Res 621:189-199.

Zhou XF, Rush RA (1994) Localization of neurotrophin-3-like immunoreactivity in the rat central nervous system. Brain Res 643:162-172. 